\title{
A importância do controle do biofilme dentário: uma revisão da literatura
}

\author{
The importance of dental biofilme control: a review of the literature
}

La importancia del controle de la biopelícula dentaria: una revisión literaria

Maria Luíza Ferraz Vasconcelos de Menezes ${ }^{1}$, Yngrid Viviane Gomes de Macedo², Nathalia Marília Pereira Ferraz ${ }^{1}$, Kaique de Freitas Matos ${ }^{2}$, Raqueline Oliveira Pereira ${ }^{2}$, Natasha Muniz Fontes $^{3}$, Mara Ilka Holanda de Medeiros Batista ${ }^{4}$, Marcília Ribeiro Paulino ${ }^{2 *}$.

\section{RESUMO}

Objetivo: Verificar a importância do controle do biofilme dentário através de uma revisão crítica da literatura. Métodos: Foram acessadas bases de dados online (PubMed, BVS e Scielo), empregando-se os seguintes termos de busca em português e inglês: Controle Químico da placa dentária, Dieta Cariogênica, Remoção da Placa Oral, Nutrição e Dieta na Formação de Biofilmes, Controle mecânico da placa oral, Método controle biofilme dental e Dentifrícios fluoretados prevenção da cárie. Consideraram-se artigos publicados nos últimos 12 anos, disponíveis para leitura completa. Todos os registros tiveram o título e resumo lidos, para confirmação de pertinência temática. Resultados: Fizeram parte da revisão 23 artigos. Foram detalhados em tabela de resultados os artigos de pesquisa e revisão sistemática $(n=16)$. A escovação dentária convencional utilizando dentifrício é eficaz no controle do biofilme, o que foi ratificado nos artigos que compararam diferentes métodos para controle de biofilme ou avaliaram impacto de diferentes hábitos de higiene oral. Considerações finais: O controle do biofilme é importante na prevenção das doenças cárie e dos problemas periodontais. Os métodos de higiene oral mostram-se como a melhor maneira de evitar patologias bucais causadas pelo biofilme bacteriano e devem ser empregados de diferentes formas, de acordo com o perfil de cada paciente.

Palavras-chave: Antissépticos bucais, Dentifrícios, Escovação dentária, Placa dentária.

\section{ABSTRACT}

Objective: Verify the importance of controlling dental biofilm through a critical review of the literature. Methods: Online databases (PubMed, BVS and Scielo) were accessed, using the following search terms in Portuguese and English: Chemical Control of dental plaque, Cariogenic Diet, Oral Plaque Removal, Nutrition and Diet in Biofilm Formation, Mechanical control of oral plaque, Dental biofilm control method and dentifrices fluoride caries prevention. Articles published in the last 12 years, available for full reading were considered. All records had the title and abstract read, to confirm the thematic pertinence. Results: 23 articles were part of the review. Research articles and systematic reviews $(n=16)$ were detailed in results table. Conventional tooth brushing using toothpaste is effective in controlling biofilm, which was confirmed in articles that compared different methods for biofilm control or that evaluated the impact of different oral hygiene habits. Final considerations: Biofilm control is important in preventing caries and periodontal problems. Oral hygiene methods are shown to be the best way to avoid oral pathologies caused by bacterial biofilm and must be used in different ways, according to each patient's profile.

Key words: Mouthwashes, Dentifrices, Toothbrushing, Dental plaque.

\section{RESUMEN}

Objetivo: Verificar la importancia del control de la biopelícula dental mediante una revisión crítica de la literatura. Métodos: Se accedió a bases de datos online (PubMed, BVS e Scielo), empleándose los siguientes términos de búsquedas en portugués e inglés: Control Químico de la placa dental, Dieta Cariogénica, Eliminación de la Placa oral, Nutrición y Dieta en la Formación de Biopelículas, Control mecánico de la placa oral, Método de control de la biopelícula dental y Dentífricos fluorados para la prevención de caries. Se consideran artículos publicados en los últimos años disponibles para su lectura completa. Todos los registros tuvieron el título y resumen leídos para confirmar la pertinencia temática. Resultados: Fueron parte de la revisión 23 artículos. Fueron detallados en la tabla de resultados los artículos de investigación y revisión sistemática $(n=16)$. El cepillado dental convencional que utiliza dentífrico es eficaz en el control de la biopelícula, lo cual fue ratificado en los artículos que compararon diferentes métodos para el control de la biopelícula o evaluaron el impacto de diferentes hábitos de higiene oral. Consideraciones finales: El control de la biopelícula es importante en la prevención de las enfermedades de la carie y de los problemas periodontales. Los métodos de higiene oral se demostraron como la mejor manera de evitar patologías bucales causadas por la biopelícula bacteriana y deben ser empleados de diferentes maneras, de acuerdo con el perfil de cada paciente.

Palabras clave: Enjuagues bucales, Dentífricos, Cepillado dental, Placa dental.

${ }^{1}$ Centro Universitário Maurício de Nassau (UNINASSAU), Recife - PE. *E-mail: marcilia.paulino@yahoo.com.br

${ }^{2}$ Centro Universitário Dr, Leão Sampaio (UNILEÃO), Juazeiro do Norte - CE.

${ }^{3}$ Centro Universitário Católica de Quixadá (UNICATÓLICA), Quixadá - CE.

${ }^{4}$ Centro Universitário de João Pessoa (UNIPÊ), João Pessoa - PB. 


\section{INTRODUÇÃO}

O biofilme ou placa dentária é formado por uma massa concentrada e sólida, rica em polissacarídeos não calcificados e glicoproteínas salivares firmemente aglutinadas às faces dentárias ou a possíveis superfícies que estejam presentes na cavidade oral, onde na grande maioria essa placa desenvolve-se sobre a película adquirida, sendo esta o biofilme que envolve toda a cavidade bucal (GONÇALVES EM, et al., 2010).

Os colonizadores prevalecentes ao longo dos primeiros estágios do acúmulo da placa subgengival são Streptococcus e Actinomyces, ao mesmo tempo em que os colonizadores secundários em sua maioria tendem a ser mais patogênicos, como tannarella forsythia, porphyromonas gingivalis, fusobacterium nucleatum, treponema denticola e actinobacillus actinomycetemcomitans (RODE SM, et al., 2012).

A relevância da placa bacteriana como fator etiológico da doença cárie e demais doenças periodontais está claramente estabelecida em literatura. Paralelamente, sua remoção mecânica, como também intervenções profissionais para higiene bucal, estão intrinsicamente relacionadas à prevenção e tratamento da cárie como também das doenças periodontais (ZANATTA FB, et al., 2012).

A escovação, eficaz e adequadamente realizada é o principal fator de desaceleração do crescimento microbiano. A remoção do biofilme bacteriano é imprescindível para manutenção da saúde bucal, os métodos químicos e mecânicos são de alta confiabilidade para realização do controle da placa bacteriana, devendo ser utilizados de forma conjunta (ANSARI G, et al., 2020; PITHON MM, et al., 2017).

Estudos relatam a eficácia de antissépticos bucais contendo ingredientes ativos como clorexidina e óleos essenciais utilizados de forma adjunta aos procedimentos de escovação e uso de fio dental para a prevenção e controle da gengivite e biofilme (FILOGÔNIO CFB, et al., 2011).

Segundo a Pesquisa Nacional de Saúde Bucal (Projeto SBBrasil 2010), inquérito que informa sobre as condições da saúde bucal da população brasileira, o percentual de pessoas com problemas no periodonto é de $37 \%$ para a idade de 12 anos, 49,1\% para faixa de 15 a 19 anos, $82,2 \%$ para adultos de 35 a 44 anos e $98,2 \%$ nos idosos de 65 a 74 anos. Compreende-se então que o controle da placa bacteriana ainda é deficiente na população em geral.

Assim, o objetivo deste trabalho foi a realização de uma revisão crítica da literatura sobre a importância do controle do biofilme dentário.

\section{MÉTODOS}

Para realização deste trabalho foram acessadas as bases de dados online: PubMed, Biblioteca Virtual de Saúde (BVS) e Scientific Electronic Library Online (Scielo). Os termos de busca e idiomas usados em cada base de dados são detalhados na (Tabela 1).

Foram considerados artigos publicados nos últimos 12 anos, cujo texto completo estivesse disponível para leitura integral, ou seja, fosse de acesso livre. Todos os títulos e resumos dos registros encontrados foram lidos, e os artigos cuja pertinência temática foi estabelecida pela leitura do título e resumo, foram selecionados para leitura completa.

Fizeram parte da revisão da literatura, os artigos lidos por completo, que responderam aos questionamentos sobre os métodos de higiene oral e qual a sua importância para a saúde bucal dos pacientes, totalizando 23 artigos. Artigos de opiniões, teses, dissertações e casos clínicos, foram excluídos da revisão. Foram incluídos e detalhados na tabela de resultados artigos de pesquisa e revisões sistemáticas. A estratégia de busca é detalhada no fluxograma (Figura 1).

Alguns artigos não foram detalhados na tabela de resultados por representarem revisões de literatura não sistemáticas (PEDRAZZI V, et al., 2009; KUBO FMM e MIALHE FL, 2011; MARTINS RS, et al., 2012; RODE SM, et al., 2012). Outros dois artigos eram ensaios clínicos com outros enfoques temáticos (LANG T, et al., 2014; VERDE ME, et al., 2015) e um dos artigos tratava-se de um estudo in vitro (VERKAIK MJ, et al., 2010). 
Tabela 1 - Termos de busca por bases de dados e idioma. Juazeiro do Norte-CE, 2020.

\section{BVS e Scielo (Português)}

Controle Químico da placa dentária

Dieta cariogênica

Remoção da placa oral

Nutrição e dieta na formação de biofilmes

Controle mecânico da placa oral

Método controle biofilme dental

Dentifrícios fluoretados prevenção da cárie

\section{PubMed (Inglês)}

Chemical control dental plaque

Cariogenic diet

Oral Plaque Removal

Nutrition and diet in biofilm formation

Mechanical control of dental plaque

Dental biofilm control method

Dentifrices fluoride caries prevention

Fonte: Menezes MLFV, et al., 2020.

Figura 1 - Fluxograma: estratégia de busca. Juazeiro do Norte-CE, 2020.

Total da Pesquisa nos bancos de dados eletrônicos:

PubMed: 7063/ BVS: 4555/ Scielo: 69

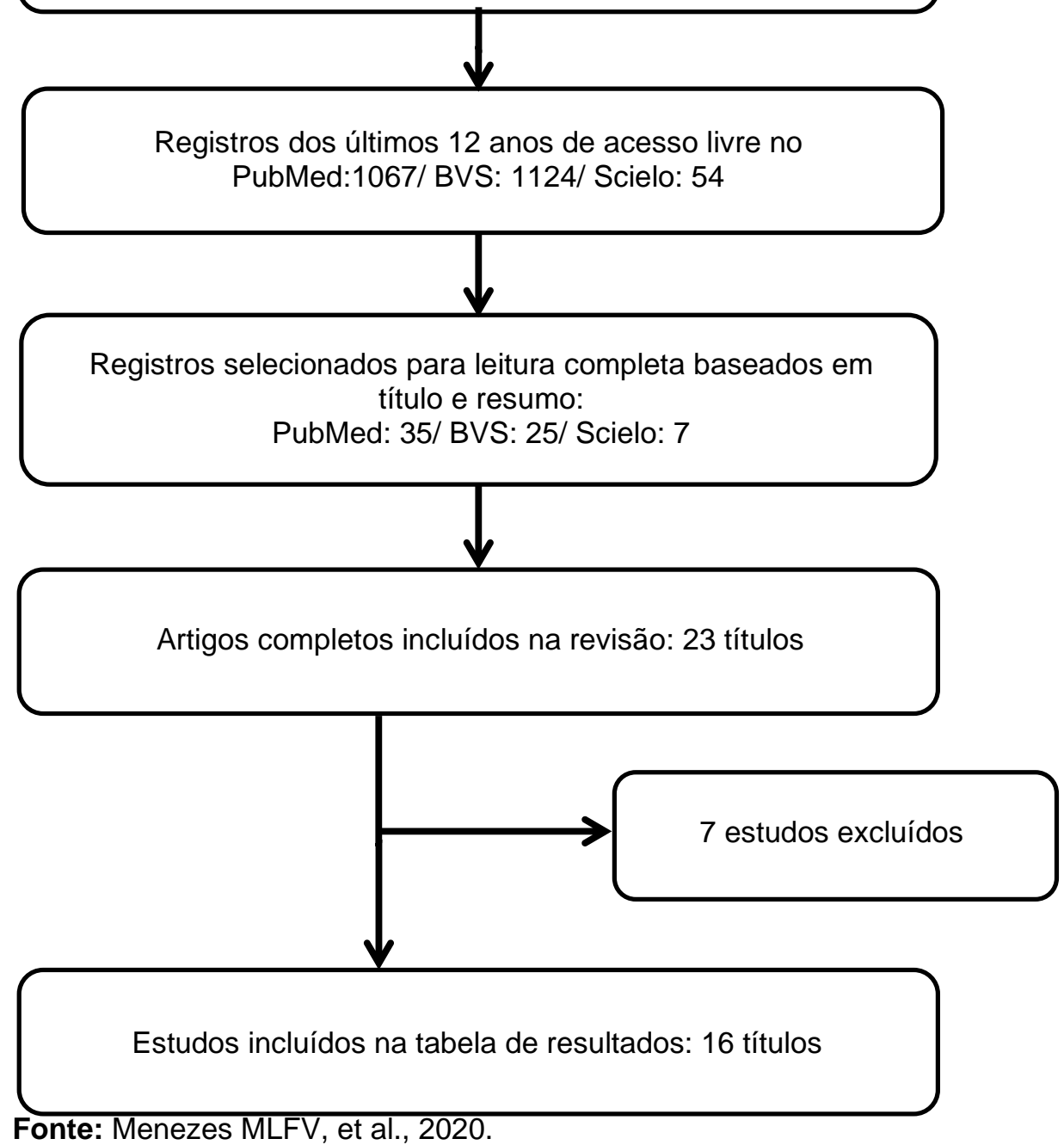

\section{RESULTADOS}

Os 16 artigos de pesquisa e revisão sistemática são detalhados quanto ao tipo de estudo, amostra, objetivos, instrumentos de avaliação e principais resultados e conclusões (Tabela 2). 


\section{Revista Eletrônica Acervo Saúde / Electronic Journal Collection Health ｜ ISSN 2178-2091}

Tabela 2 - Artigos detalhados em tabela de resultados, $n=16$. Juazeiro do Norte-CE, 2020.

\begin{tabular}{|c|c|c|c|c|c|}
\hline $\begin{array}{l}\text { AUTOR } \\
\text { (ANO) }\end{array}$ & TIPO DE ESTUDO & AMOSTRA & OBJETIVO & INSTRUMENTOS UTILIZADOS & $\begin{array}{c}\text { PRINCIPAIS RESULTADOS E } \\
\text { CONCLUSÕES }\end{array}$ \\
\hline $\begin{array}{l}\text { Gonçalves EM, et } \\
\text { al., } 2010 .\end{array}$ & Estudo Transversal & $\begin{array}{l}\mathrm{N}=165 \\
\text { (dentistas) }\end{array}$ & $\begin{array}{l}\text { Avaliar o conhecimento de } \\
\text { dentistas sobre a prescrição } \\
\text { de colutórios e dentifrícios. }\end{array}$ & $\begin{array}{l}\text { Entrevista: } 5 \text { perguntas sobre } \\
\text { prescrição e composição de } \\
\text { colutórios e dentifrícios bucais. }\end{array}$ & $\begin{array}{l}\text { O colutório mais indicado foi o Periogard } \\
\text { (33,3\%); O Princípio ativo com mais } \\
\text { acertos foi a clorexidina ( } 80 \%) \text {. Entretanto, } \\
\text { apenas } 17,6 \% \text { responderam corretamente } \\
\text { o regime terapêutico da clorexidina; O } \\
\text { Dentifrício mais indicados foi da marca } \\
\text { Colgate } 52,7 \% \text {. e } 60 \% \text { acertaram o } \\
\text { ingrediente ativo na Colgate total } 12 \text {. }\end{array}$ \\
\hline $\begin{array}{l}\text { Haas AN, et al., } \\
2010\end{array}$ & Estudo Transversal & $\begin{array}{l}\mathrm{N}=93 \text { (Estudantes de } \\
\text { odontologia) }\end{array}$ & $\begin{array}{l}\text { Avaliar o conhecimento de } \\
\text { estudantes de Odontologia a } \\
\text { respeito de antissépticos } \\
\text { bucais. }\end{array}$ & $\begin{array}{l}\text { Foi aplicado um questionário } \\
\text { estruturado avaliando o } \\
\text { conhecimento dos alunos sobre } \\
\text { antissépticos orais. }\end{array}$ & $\begin{array}{l}\text { A Clorexidina foi considerada por todos } \\
\text { padrão-ouro para prescrição após cirurgias } \\
\text { bucais; O Triclosan foi considerado por } \\
62,8 \% \text { dos estudantes como o antisséptico } \\
\text { com maior benefício clínico. Já } 1 / 4 \text { dos } \\
\text { estudantes não souberam responder qual } \\
\text { o agente mais benéfico e } 62,5 \% \text { dos } \\
\text { estudantes não souberam responder qual } \\
\text { a prescrição correta de óleos essenciais. }\end{array}$ \\
\hline $\begin{array}{l}\text { Jayakumar A, et al., } \\
2010\end{array}$ & $\begin{array}{l}\text { Ensaio clínico } \\
\text { controlado } \\
\text { randomizado } \\
\text { (cruzado) }\end{array}$ & $\begin{array}{l}\mathrm{N}=42 \text { (estudantes a partir } \\
\text { de } 18 \text { anos e com pelo } \\
\text { menos } 5 \text { dentes por arcada } \\
\text { para avaliação); } \mathrm{GA}(\mathrm{n}=21) \text { : } \\
\text { escovação sem dentifrício; } \\
\mathrm{GB}(\mathrm{n}=21) \text { : escovação com } \\
\text { dentifrício }\end{array}$ & $\begin{array}{l}\text { Papel do dentifrício na } \\
\text { remoção da placa dentária. }\end{array}$ & $\begin{array}{l}\text { Após } 48 \text { h de acúmulo de placa, foi } \\
\text { feita a análise da quantidade de placa } \\
\text { antes e após a escovação pela, em } \\
\text { ambos os grupos; Todos os } \\
\text { participantes foram avaliados pelas } 2 \\
\text { técnicas (cruzamento), com intervalo } \\
\text { de } 1 \text { semana. }\end{array}$ & $\begin{array}{l}\text { Redução da placa: } \\
\text { Com dentifrício > Sem dentifrício } \\
(p \leq 0,001)\end{array}$ \\
\hline $\begin{array}{l}\text { Filogônio CFB, et } \\
\text { al., } 2011 .\end{array}$ & $\begin{array}{l}\text { Ensaio Clínico } \\
\text { Controlado } \\
\text { Randomizado. }\end{array}$ & $\begin{array}{l}\mathrm{N}=30 \text { (23 mulheres e } 7 \\
\text { homens/ Idade: } 18-21 \text { anos); } \\
\mathrm{G} 1(\mathrm{~N}=10) \text { : dentifrício } \\
\text { disponível no mercado. } \mathrm{G} 2 \\
(\mathrm{~N}=10): \text { dentifrício do } \mathrm{G} 1+ \\
\text { Óleo mineral lí́uido; } \mathrm{G} 3 \\
\text { ( } \mathrm{N}=10 \text { ): dentifríio do } \mathrm{G} 1+ \\
\text { óleo de castanha. }\end{array}$ & $\begin{array}{l}\text { Avaliar a eficácia da adição } \\
\text { de óleo vegetal ou mineral a } \\
\text { um dentifrício comercialmente } \\
\text { disponível no controle de } \\
\text { biofilme dental. }\end{array}$ & $\begin{array}{l}\text { Índice de Higiene oral simplificado } \\
\text { avaliado no tempo baseline, } 45 \text { e } 90 \\
\text { dias. }\end{array}$ & $\begin{array}{l}\text { Redução no IHO-S no dia 90: G2>G1 ( } p \\
<0,05) \text {, G3>G1 }(p<0,0001) \text {; Adição de um } \\
\text { óleo vegetal ou mineral a um dentifrício } \\
\text { comercialmente disponível melhorou o } \\
\text { controle do biofilme dentário. }\end{array}$ \\
\hline $\begin{array}{l}\text { Zanatta FB, et al., } \\
2012 .\end{array}$ & $\begin{array}{l}\text { Ensaio Clínico } \\
\text { Controlado } \\
\text { Randomizado cego. }\end{array}$ & $\begin{array}{l}\mathrm{N}=24 \text { (estudantes de } 17 \text { a } \\
28 \text { anos); GE: escovação } \\
\text { sem dentifrício; GC: } \\
\text { escovação com dentifrício. }\end{array}$ & $\begin{array}{l}\text { Comparar a eficácia da } \\
\text { remoção da placa dentária } \\
\text { por escovação com e sem } \\
\text { dentifrício convencional. }\end{array}$ & $\begin{array}{l}\text { Após } 72 \text { h de interrupção da higiene } \\
\text { bucal, o índice de placa foi avaliado } \\
\text { antes e após a escovação por um } \\
\text { examinador calibrado e cego. }\end{array}$ & $\begin{array}{l}\text { Não houve diferenças estatisticamente } \\
\text { significativas entre os grupos. Ambos } \\
\text { foram eficazes na remoção de placa. }\end{array}$ \\
\hline
\end{tabular}




\begin{tabular}{|c|c|c|c|c|c|}
\hline $\begin{array}{l}\text { AUTOR } \\
\text { (ANO) }\end{array}$ & TIPO DE ESTUDO & AMOSTRA & OBJETIVO & INSTRUMENTOS UTILIZADOS & $\begin{array}{c}\text { PRINCIPAIS RESULTADOS E } \\
\text { CONCLUSÕES }\end{array}$ \\
\hline $\begin{array}{l}\text { Pivotto A, et al., } \\
2013 .\end{array}$ & Estudo Transversal. & $\begin{array}{l}\mathrm{N}=202 \text { (estudantes do } \\
\text { ensino fundamental); Idade: } \\
\text { estudantes do primeiro ano } \\
\text { do ensino fundamental. }\end{array}$ & $\begin{array}{l}\text { Verificar os hábitos de } \\
\text { limpeza oral e a taxa de } \\
\text { higiene bucal de estudantes. }\end{array}$ & $\begin{array}{l}\text { Questionário sobre a caracterização } \\
\text { da limpeza oral dos estudantes } \\
\text { (respondido pelos pais); Exame } \\
\text { clínico: Índice de Higiene Oral } \\
\text { Simplificado (IHOS); }\end{array}$ & $\begin{array}{l}\text { Estudantes com hábitos de limpeza oral } \\
\text { ruim para remoção do biofilme e no uso do } \\
\text { fio dental; Foi visto que } 16,8 \% \text { das } \\
\text { crianças avaliadas tem o IHOS bom, } \\
56,4 \% \text { razoável e } 26,7 \% \text { deficiente; } 59,9 \% \\
\text { relataram que um adulto é responsável } \\
\text { pela escovação; } 40,1 \% \text { informaram que a } \\
\text { própria criança executa a escovação; } \\
\text { Apenas } 32 \% \text { fazem uso do fio dental. }\end{array}$ \\
\hline $\begin{array}{l}\text { Costa A, et al., } \\
2014\end{array}$ & Estudo Transversal. & $\begin{array}{l}\mathrm{N}=100 \text { crianças/ } \\
\text { escovas; Idade: } 6 \text { a } 13 \text { anos. }\end{array}$ & $\begin{array}{l}\text { Analisar as taxas de placa } \\
\text { bacteriana e precaução } \\
\text { referente a forma e limpeza } \\
\text { das escovas de dentes das } \\
\text { crianças. }\end{array}$ & $\begin{array}{l}\text { Índice de placa: Índice de higiene oral } \\
\text { Podshadley e Halley (varia de 0-5); } \\
\text { Condição das escovas: Escala de } \\
\text { deterioração de escovas. }\end{array}$ & $\begin{array}{l}\text { Índice de biofilme e deterioração das } \\
\text { escovas dentárias: Índice de biofilme 2: } 40 \\
\text { crianças; sendo } 37,5 \% \text { estágio } 2 \text { de } \\
\text { deterioração de escova dentária; Índice de } \\
\text { Placa 3: } 48 \text { crianças; sendo } 45,8 \% \text { estágio } \\
1 \text { de deterioro de escova dentária; } \\
\text { Armazenamento Individual: Modo de } \\
\text { desinfecção apenas água } \\
\text { Troca de escovas: 6-12 meses. }\end{array}$ \\
\hline $\begin{array}{l}\text { Mahajan N, et al., } \\
2014\end{array}$ & $\begin{array}{l}\text { Ensaio Clínico } \\
\text { Controlado. }\end{array}$ & $\begin{array}{l}\mathrm{N}=10 \text { crianças (Idades: 8-15 } \\
\text { anos); G1: suco de laranja } \\
\text { sem açúcar; G2: suco de } \\
\text { laranja açucarado; G3: suco } \\
\text { de maça sem e com adição } \\
\text { de açúcar; G4: suco de } \\
\text { maça sem e com adição de } \\
\text { açúcar; GC: Lavagem com } \\
\text { sacarose (10\%) }\end{array}$ & $\begin{array}{l}\text { Influência dos sucos "com" ou } \\
\text { "sem" adição de açúcares no } \\
\text { Ph da placa. }\end{array}$ & $\begin{array}{l}\text { Foi calculado o índice de potencial } \\
\text { cariogênico (IPC); Foi utilizado um } \\
\text { medidor de Ph digital: Ph endógenos } \\
\text { dos sucos de fruta e controle; Ph da } \\
\text { placa: tempo inicial e } 5,10,20,30,40 \text { e } \\
60 \text { minutos após ingestão das } \\
\text { bebidas. }\end{array}$ & $\begin{array}{l}\text { Todos os sucos reduziram o Ph. } \\
\text { Índice de potencial cariogênico (IPC) dos } \\
\text { sucos: Suco de laranja com açúcar }(2,16) ; \\
\text { suco de laranja não açucarado }(1,82) ; \text { suco } \\
\text { de maça sem açúcar }(1,13) ; \text { suco de maça } \\
\text { com açúcar }(1,11) \text {. Os autores concluúram } \\
\text { que independente do suco ser "com" ou } \\
\text { "sem" adição de açúcares, todos são } \\
\text { cardiogênicos. }\end{array}$ \\
\hline $\begin{array}{l}\text { Ferreira R, et al., } \\
2016\end{array}$ & Revisão Sistemática. & $\begin{array}{l}\mathrm{N}=9 \text { (4 estudos longitudinais; } \\
4 \text { ensaios clínicos e } 1 \text { série } \\
\text { de casos prospectivos) }\end{array}$ & $\begin{array}{l}\text { Avaliar qual tipo de } \\
\text { abordagem preventiva e } \\
\text { terapêutica periodontal que } \\
\text { apresentem resultados } \\
\text { superiores em paciente com } \\
\text { trissomia do cromossomo } 21 \text {. }\end{array}$ & Não se aplica. & $\begin{array}{l}\text { A introdução diária e regular da escovação } \\
\text { e da visita ao cirurgião-dentista como } \\
\text { prevenção dos cuidados periodontais, } \\
\text { associado a agentes químicos melhora os } \\
\text { resultados de saúde bucal dos pacientes } \\
\text { com síndrome de Down, assim como a } \\
\text { participação dos pais/ cuidadores. }\end{array}$ \\
\hline
\end{tabular}

REAS/EJCH | Vol.Sup.n.55 | e3698 | DOI: https://doi.org/10.25248/reas.e3698.2020 Página $\mathbf{5}$ de 12 


\begin{tabular}{|c|c|c|c|c|c|}
\hline $\begin{array}{l}\text { AUTOR } \\
\text { (ANO) }\end{array}$ & TIPO DE ESTUDO & AMOSTRA & OBJETIVO & INSTRUMENTOS UTILIZADOS & $\begin{array}{c}\text { PRINCIPAIS RESULTADOS E } \\
\text { CONCLUSÕES }\end{array}$ \\
\hline $\begin{array}{l}\text { Rodrigues AP, et } \\
\text { al., } 2016\end{array}$ & Quase- experimental & $\begin{array}{l}\mathrm{N} \text { (inicial): } 256 ; \mathrm{N} \text { (final): } 190 \\
\text { (escolares/ Idade: 3-7 anos); } \\
\text { Nova avaliação: em média } \\
\text { após } 106 \text { dias. }\end{array}$ & $\begin{array}{l}\text { Alteração no índice de placa } \\
\text { após intervenção (escovação } \\
\text { em ambiente escolar). }\end{array}$ & $\begin{array}{l}\text { Índice CPO-d e Índice de placa } \\
\text { avaliados antes e após a intervenção; } \\
\text { Intervenção: implementação da } \\
\text { escovação diária na escola; } \\
\text { Avaliação inicial e final (em média } \\
\text { após } 106 \text { dias da intervenção). }\end{array}$ & $\begin{array}{l}\text { Índice de CPOD não mudou } \\
\text { significativamente (provavelmente fator } \\
\text { tempo para reavaliação esteja associado). } \\
\text { Índice de Placa: Índice de Placa Inicial: } \\
2,83 \text {; Índice de Placa Final: } 0,40 ; \text { Reduc̃ão } \\
\text { significativa da placa bacteriana dentária } \\
\text { em crianças em idade pré-escolar que } \\
\text { realizam a escovação dentária em } \\
\text { ambiente escolar. }\end{array}$ \\
\hline $\begin{array}{l}\text { Pithon MM, et al., } \\
2017\end{array}$ & $\begin{array}{l}\text { Revisão sistemática e } \\
\text { metanálise. }\end{array}$ & $\begin{array}{l}\mathrm{N}=23 \text { (17 estudos foram } \\
\text { considerados de alto padrão } \\
\text { metodológico e } 6 \text { de } \\
\text { qualidade moderada. A } \\
\text { metanálise incluiu } 6 \text { artigos) }\end{array}$ & $\begin{array}{l}\text { Responder à pergunta focal: } \\
\text { os métodos mecânicos de } \\
\text { limpeza oral são eficazes } \\
\text { para a redução da placa } \\
\text { bacteriana dentária em } \\
\text { pacientes com aparelho } \\
\text { ortodôntico fixo? }\end{array}$ & Não se aplica. & $\begin{array}{l}\text { Os autores concluíram que o uso da } \\
\text { escova manual convencional é eficaz na } \\
\text { redução do índice de placa em pacientes } \\
\text { que usam aparelhos ortodônticos fixos. }\end{array}$ \\
\hline $\begin{array}{l}\text { Ribeiro AA, et al., } \\
2017\end{array}$ & Estudo Transversal & $\begin{array}{l}\mathrm{N}=13 \text { crianças; Idade: } 12 \\
\text { anos }\end{array}$ & $\begin{array}{l}\text { Avaliar diversidade bacteriana } \\
\text { e sua relação com o } \\
\text { diagnóstico clínico de } \\
\text { superfícies e hábitos } \\
\text { alimentares. }\end{array}$ & $\begin{array}{l}\text { Entrevistar as crianças e os pais } \\
\text { através de um questionário de } \\
\text { freqüência alimentar. }\end{array}$ & $\begin{array}{l}\text { Acúmulo de biofilme: Alto em } 9 \text { das } 13 \\
\text { crianças. CPOD: Valores altos } \\
4,31 \text { (média); maioria dos indivíduos ( } 9 \text { das } \\
\text { 13) consumia carboidratos fermentáveis } \\
\text { (açúcares e amido) em alta freqüência } \\
\text { ( } \geq 2 X / \text { dia). A principal fonte de flúor: } \\
\text { creme dental. }\end{array}$ \\
\hline $\begin{array}{l}\text { Velázquez FA, et } \\
\text { al., } 2017\end{array}$ & $\begin{array}{l}\text { Ensaio clínico } \\
\text { controlado } \\
\text { randomizado }\end{array}$ & $\begin{array}{l}\mathrm{N}=40 \text { estudantes de } \\
\text { odontologia ( } 18-30 \text { anos.); } \\
\text { GC: Fio dental tradicional; } \\
\text { GE: fio dental laçado } \\
\text { (amarrado, formato de anel). }\end{array}$ & $\begin{array}{l}\text { Comparar o controle do } \\
\text { biofilme dental através do uso } \\
\text { de fio dental tradicional ou } \\
\text { laçado. }\end{array}$ & $\begin{array}{l}\text { Cada paciente usou durante } 45 \text { dias } \\
\text { cada um dos métodos para limpeza } \\
\text { interdentária. Foram coletados: Îndice } \\
\text { de Placa; Índice de Sangramento à } \\
\text { sondagem/ Coleta de fluido gengival } \\
\text { interdentário para avaliação da } \\
\text { concentração de interleucinas (IL-6 e } \\
\text { IL-8); A avaliação ocorreu no tempo } \\
\text { baseline, } 15 \text { e } 45 \text { dias, para cada } \\
\text { protocolo (cada paciente era seu } \\
\text { próprio controle). }\end{array}$ & $\begin{array}{l}\text { Melhora no Índice de Placa: GE>GC } \\
\text { (p<0,05); Não houve diferença } \\
\text { estatisticamente significativa entre os } \\
\text { grupos em relação as outras variáveis } \\
\text { avaliadas. }\end{array}$ \\
\hline
\end{tabular}

REAS/EJCH | Vol.Sup.n.55 | e3698 | DOI: https://doi.org/10.25248/reas.e3698.2020 Página 6 de 12 


\section{Revista Eletrônica Acervo Saúde / Electronic Journal Collection Health ｜ ISSN 2178-2091}

\begin{tabular}{|c|c|c|c|c|c|}
\hline $\begin{array}{l}\text { AUTOR } \\
\text { (ANO) }\end{array}$ & TIPO DE ESTUDO & AMOSTRA & OBJETIVO & INSTRUMENTOS UTILIZADOS & $\begin{array}{c}\text { PRINCIPAIS RESULTADOS E } \\
\text { CONCLUSÕES }\end{array}$ \\
\hline $\begin{array}{l}\text { Figuero E, et al., } \\
2019\end{array}$ & Revisão sistemática & $\begin{array}{l}\mathrm{N}=70 \text { (70 estudos de } \\
\text { antisséptico). }\end{array}$ & $\begin{array}{l}\text { Avaliar a eficácia de terapias } \\
\text { adjuvantes na redução de } \\
\text { gengivite e placa bacteriana } \\
\text { por meio de uma revisão } \\
\text { sistemática de ensaios } \\
\text { clínicos randomizados. }\end{array}$ & Não se aplica. & $\begin{array}{l}\text { Os antissépticos adjuvantes nos } \\
\text { enxaguatórios bucais e dentifrícios } \\
\text { contribuem para uma redução } \\
\text { estatisticamente significativa nos índices } \\
\text { de placa e de sangramento gengival. }\end{array}$ \\
\hline Adam R, et al. 2020 & $\begin{array}{l}\text { Ensaio clínico } \\
\text { controlado } \\
\text { randomizado } \\
\text { (cruzado) }\end{array}$ & $\begin{array}{l}\mathrm{N}=27 \\
\text { (idade média } 42 \text { anos). } \\
\text { Todos passaram por } 4 \\
\text { períodos de avaliação. }\end{array}$ & $\begin{array}{l}\text { Avaliar o potencial de } \\
\text { remoção de placa bacteriana } \\
\text { de uma escova de dentes } \\
\text { elétrica em comparação com } \\
\text { uma escova de dentes } \\
\text { manual. }\end{array}$ & $\begin{array}{l}\text { Os participantes foram orientados a } \\
\text { não realizar higienização } 12 \mathrm{~h} \text { antes } \\
\text { da avaliação do estudo; Houve quatro } \\
\text { períodos de avaliação; } \\
\text { A quantidade de placa era avaliada } \\
\text { antes e após a escovação, com } \\
\text { dentifrício e escova designada para } \\
\text { cada momento. Todos usaram cada } \\
\text { uma das escovas de dente duas } \\
\text { vezes. }\end{array}$ & $\begin{array}{l}\text { A escova elétrica oscilatória foi } \\
\text { estatisticamente superior à escova manual } \\
\text { na remoção de placa bacteriana }\end{array}$ \\
\hline $\begin{array}{l}\text { Ansari G, et al., } \\
2020\end{array}$ & Ensaio clínico cruzado & $\begin{array}{l}\mathrm{N}=43 \text { (crianças de } 10 \text { a } 12 \\
\text { anos selecionadas } \\
\text { aleatoriamente); G1 } \\
\text { (escovação com a técnica } \\
\text { seca); G2 (escovação com a } \\
\text { técnica úmida). }\end{array}$ & $\begin{array}{l}\text { - Avaliar a eficácia da } \\
\text { escovação úmida e seca no } \\
\text { resultado da limpeza das } \\
\text { superficies dentárias. }\end{array}$ & $\begin{array}{l}\text { Cada paciente foi solicitado a escovar } \\
\text { com uma das técnicas úmida/seca na } \\
\text { primeira semana e a outra técnica na } \\
\text { segunda semana. O método de } \\
\text { escovação instruído foi o Stillman } \\
\text { modificado; O índice de placa foi } \\
\text { avaliado nas superfícies dos } \\
\text { elementos } 11,16,26,31,36 \text { e } 46 \\
\text { após aplicação de solução } \\
\text { evidenciadora. }\end{array}$ & $\begin{array}{l}\text { Não houve diferenças estatísticamente } \\
\text { significativas entre as técnicas. }\end{array}$ \\
\hline
\end{tabular}

Legenda: CPOD (Dentes Cariados Perdidos Obturados); IHOS (Índice de Higiene Oral Simplificado); API (Índice de Potencial Acidogênico); G (Grupo); N (Amostra); GC (Grupo de Controle); GE (Grupo de Estudo).

Fonte: Menezes MLFV, et al., 2020. 


\section{DISCUSSÃO}

As patologias que mais afetam o sistema estomatognático são doenças periodontais e lesões cariosas, tendo como fator etiológico primário a placa dentária, compreendido não só como aglomerado de bactérias, mas sim como um biofilme bacteriano, formado principalmente pelo alto consumo de sacarose associado a má higienização oral (COSTA A, et al., 2014).

Quando não higienizado corretamente o meio bucal torna-se um ambiente propício para proliferação dos patógenos. Sabe-se que há uma associação direta entre a competência da higiene oral, o número e qualidade do biofilme dentário, predominância e magnitude da doença, contudo, a doença periodontal e a cárie têm um valor predominante na população, indicando uma quantidade significativa de pessoas que não desempenham um controle adequado do biofilme (FILOGÔNIO CFB, et al., 2011; MARTINS RS, et al., 2012).

Esse biofilme, também conferido como placa bacteriana, prende-se as superfícies dos dentes, apresentando-se como agente determinante de lesões cariosas e doenças englobando tecido gengival e o osso que circunda a raiz do dente, podendo acarretar patologias mais severas e até a perda do elemento dentário, particularizando-se essencialmente como a maior preocupação dos cirurgiões-dentistas na prática da intervenção e prevenção (PIVOTTO A, et al., 2013).

A placa bacteriana se adere firmemente às superfícies dentárias, contendo grandes quantidades de microrganismos, decorrente da falta de medidas de higiene oral adequada que contribuem na formação do biofilme bacteriano patogênico, desequilibrando o processo de saúde-doença, acumulando-se em grandes dimensões superando o limite de resistência do hospedeiro, atingindo estruturas dentárias e tecidos de suporte (MARTINS RS, et al., 2012; RODE SM, et al., 2012).

A doença periodontal é uma patologia inflamatória multifatorial, que tem como principal razão a presença do biofilme patogênico, associado aos fatores ligados ao hospedeiro, como aspectos ambientais, tabagismo ou ingestão de algumas drogas, condições importantes para prevalência e gravidade da doença (VERDE $\mathrm{ME}$, et al., 2015). A doença cárie também se desenvolve associada ao incorreto controle do biofilme. Alimentos com a presença de altos níveis de carboidratos fermentáveis quando metabolizados por microrganismos de biofilme produzem ácidos orgânicos que levam a baixa no ph da placa oral podendo gerar a desmineralização e consequentemente a lesão cariosa, isso acontece porque a placa dental é um biossistema microbiano ativo e seguro e a cárie dental é uma patologia biofilme-sacarose dependente, levando a uma perda mineral (MAHAJAM N, et al., 2014; RIBEIRO AA, et al., 2017).

A dentina e a saliva são compostas por fosfato e cálcio, componentes que protegem suas estruturas orais naturalmente, mas dependem totalmente da forma com que o ph apresenta-se, fazendo a lesão cariosa ser uma doença oportunista infecciosa, de uma combinação de fatores, influenciada pela microbiota, dieta e hospedeiro (MARTINS RS, et al., 2012).

A higienização mecânica através de uma escova e um dentifrício ainda é o método mais eficaz e comum para o controle da placa supra-gengival, além disso, os dentifrícios auxiliam na diminuição do acúmulo do biofilme, revigorando os dentes contra a cárie, retirando manchas, restos de alimentos e refrescando a boca, aumentando a remoção da placa e ajudando a superar as falhas manuais ou mecânicas da escovação (JAYAKUMAR A, et al., 2010).

Geralmente, uma escova para ser ativa necessita oferecer certas condições tais como cabeça pequena; cabeça e cabo num só plano; cerdas do mesmo tamanho, macias, com pontas redondas e polidas distribuindo-se na forma multitufo. A técnica manual de escovação dentária, feita de maneira adequada tem total eficácia na remoção da placa, porém, diversas pessoas não realizam as manobras apropriadas ou não têm destreza manual satisfatória para obter efeitos clínicos aceitáveis e conceber bons resultados (RODE SM, et al., 2012; PEDRAZZI V, et al., 2009). As escovas elétricas tornam-se alternativas para essas situações, elas apresentam um nível maior de destaque científico do que as escovas dentais manuais, obtendo-se bons resultados para remoção da placa bacteriana existente nas faces livres dos elementos dentários e para o controle da gengivite (VELÁZQUEZ FA, et al., 2017). 
O fio dental é mais apropriado na limpeza das faces interproximais dos dentes, agindo como um complemento da escovação, sendo importante seu uso correto e regular para o controle do biofilme e prevenção de lesão cariosa interdental e gengivite associada à placa. Para pessoas com perda de inserção severa e moderada, o uso da escova interdental parece mais apropriado para higienização das regiões interproximais, sendo elas em diversos calibres e ângulos, promovendo a remoção de resíduos principalmente em regiões mais posteriores (KUBO FMM e MIALHE FL, 2011; VELÁZQUEZ FA, et al., 2017).

Estudos relatam a dificuldade da população quanto a forma de escovação e uso do fio-dental como uma maneira de prevenção da doença periodontal e lesão cariosa, fazendo com que o controle dessas patologias tenha melhorado quando instruções sobre a remoção do biofilme foram oferecidas mais frequentemente a população (FILOGÔNIO CFB, et al., 2011).

A dificuldade de alcançar um controle "ideal" de placa através de técnicas mecânicas levou clínicos e cientistas a buscar agentes químicos antimicrobianos que conseguissem ajudar a inibir a formação de biofilmes nas superfícies dentárias (FILOGÔNIO CFB, et al., 2011; VERKAIK MJ, et al., 2010).

A remoção química atua de forma adjunta ao domínio da escovação para melhorar os erros higiene mecânica, ocasionada por vários motivos. Assim associando métodos mecânicos a componentes químicos estimula-se um controle eficaz da placa dental, promovendo desconstrução no desenvolvimento da mesma, utilizando produtos à base de fluoretos e pirofosfatos solúveis (agentes anticálculo dentário), causando resultados antibacterianos no combate a vários patógenos orais (FILOGÔNIO CFB, et al., 2011; VERKAIK MJ, et al., 2010; GONÇALVES EM, et al., 2010).

Nos últimos dez anos, inúmeros ingredientes têm sido acrescentados aos enxaguantes e dentifrícios buscando a inibição na formação do cálculo, no controle da placa dentária, e até mesmo tratando a sensibilidade, sendo o flúor um dos agentes de maior aplicação nos produtos de higiene bucal. O flúor não é apenas considerado como um elemento preventivo contra a cárie, mas também uma substância com capacidade de remineralizar as desmineralizações associada a agradável sensação de frescor e sabor após o uso (GONÇALVES EM, et al., 2010; ZANATTA FB, et al., 2012).

A clorexidina que possui um alto espectro sobre as bactérias gram-negativas, gram-positivas, é a principal e mais efetiva escolha para o controle químico do biofilme dental, especialmente pela sua substantividade, mas também por ter uma ação antimicrobiana eficaz, tendo capacidade de diminuir a inflamação na gengiva em até $45 \%$ e a placa em até $71 \%$. Outro antibacteriano presente nos enxaguatórios orais é o triclozan, que possui rápida liberação e baixa substantividade, porém associado a outros produtos, aumenta-se seu tempo de permanência/ação na cavidade oral (MARTINS RS, et al., 2012; RODE SM, et al., 2012).

A escovação combate o biofilme principalmente as faces livres, desorganizando colônias bacterianas, e impedindo o seu desenvolvimento, de modo que, com o auxílio do fio dental utilizado de forma correta seja capaz de higienizar as faces interproximais. Já os enxaguantes bucais servem de veículos para agentes antibacterianos interagindo com a placa oral, também desorganizando as bactérias, onde alguns tem a capacidade de agir durante um período maior de tempo (PEDRAZZI V, et al., 2009).

Para incentivar os métodos de limpeza bucal e ajudar o paciente com o controle de higiene oral recomendado, novos projetos de escovas de dente são feitos e testados para diferentes grupos etários, perfis de doença de cada indivíduo, pacientes em necessidades especiais, dentre outros, exigindo formas específicas de escovas e como resultado, técnicas de escovações individuais (LANG T, et al., 2014).

Para usuários de aparelhos ortodônticos, por exemplo, exige-se um maior acompanhamento da higiene bucal e deve-se lançar mão de técnicas e instrumentos específicos, como escovas interdentais e uso da passa fio. Tais escovas permitem melhor remoção da placa dental (onde escovas convencionais não alcançam) e o passa fio permite a higienização com maior facilidade, por ser similar a uma agulha, auxiliando a passagem do fio dental pelos bráquetes ortodônticos (KUBO FMM e MIALHE FL, 2011). 
Outro grupo específico de pacientes são os portadores de Síndrome de Down. Eles estão mais susceptíveis ao desenvolvimento da doença periodontal, sendo ela grave, de rápida progressão e associada a distúrbios genéticos. As mães ou os cuidadores destes pacientes devem ser orientados quanto a sua higiene bucal, para obter-se um melhor controle do biofilme, informando-as a correta forma de higienização mecânica e a utilização do fio dental e enxaguantes bucais (FERREIRA R, et al., 2016).

O fato é que há métodos de higienização variados e a associação de métodos pode aumentar a eficácia do procedimento (PEDRAZZI V, et al., 2009). A limpeza com escova dental e utilização do fio dental realizadas em momentos regulares e de maneira correta são ações que proporcionam um eficaz controle da placa bacteriana supragengival e por consequência da lesão cariosa e das alterações gengivais (KUBO FMM e MIALHE FL, 2011).

A revisão sistemática Ferreira $R$, et al., (2016) incluída revelou a importância de programas de prevenção para a redução do índice de sangramento e inflamação gengival em pacientes com síndrome de down. Pithon MM, et al. (2017) evidenciou diferentes métodos de escovação para paciente que utilizam aparelho ortodôntico. Já Figuero E, et al. (2019) avaliou a utilização de antissépticos adjuvantes na escovação dentária. Entre os ensaios clínicos incluídos, cinco tiveram amostras de jovens e adultos a partir de 18 anos e avaliaram eficácia de diferentes métodos para o controle do biofilme: Jayakumar A, et al. (2010) e Zanatta FB, et al. (2012) estudaram a atuação específica do dentifrício na remoção da placa dentária; Filogônio CFB, et al. (2011) avaliaram a adição de um óleo vegetal ou mineral a um dentifrício comercializado; Velázquez FA, et al. (2017) avaliaram a eficácia do uso do fio dental em anel (laçado); Adam R, et al. (2020) avaliaram a utilização de uma escova com micro vibração.

Dois ensaios clínicos envolveram crianças/adolescentes de 8-15 anos; Mahajan N, et al. (2014) avaliou a influência dos alimentos no ph da placa bacteriana; enquanto Ansari G, et al. (2020) avaliou a escovação realizada com escova seca e úmida. Dentre os 5 estudos transversais, 1 foi realizado com profissionais dentistas e o outro com estudantes de odontologia visando verificar o conhecimento deles sobre colutórios orais prescritos (GONÇALVES EM, et al., 2010; HAAS NA, et al., 2010).

Sobre os demais estudos transversais, um analisou os hábitos alimentares e sua relação com o diagnóstico clínico das superfícies dentais (RIBEIRO AA, et al., 2017), e os outros 2 envolveram escolares analisando sua forma de higiene oral (PIVOTTO A, et al., 2013; COSTA A, et al., 2014), assim como o estudo quase experimental (RODRIGUES AP, et al., 2016).

Muitos trabalhos foram realizados em crianças/ escolares. Isso se justifica pelas lesões cariosas serem uma das doenças mais prevalentes da infância, causando severas dores, alterações no sono e ansiedade, e levando a grande procura de recursos de saúde (COSTA A, et al., 2014; RODRIGUES AP, et al., 2016; RIBEIRO AA, et al., 2017; ANSARI G, et al., 2020).

Entretanto, a prevenção é viável pelo controle da proliferação bacteriana através do manejo químico/mecânico do biofilme dentário. O Brasil atualmente tem reduzido o índice de cárie principalmente nos mais jovens, porém a cárie permanece o principal agravo da saúde oral das crianças (PIVOTTO A, et al., 2013). Justamente por isso, o incentivo e enfoque no aprendizado e valorização da importância da escovação devem ser na infância (COSTA A, et al., 2014; RODRIGUES AP, et al., 2016).

Costa A, et al. (2014) avaliaram o Índice de placa de 100 crianças e encontraram valores elevados. Pivotto A, et al. (2013) avaliaram o IHOS e os hábitos de higiene oral de 202 escolares e observaram que $40,1 \%$ dos pais delegarem a escovação única e exclusivamente às crianças. Os autores que fizeram estudos entre crianças de diferentes faixas etárias descrevem a importância da orientação de higiene oral para pais e responsáveis da população infantil (COSTA A, et al., 2014; PIVOTTO A, et al., 2013; RODRIGUES AP, et al., 2016; ANSARI G, et al., 2020).

Rodrigues AP, et al. (2016) realizaram um estudo classificado com estudo quase experimental, através do qual realizavam a implementação da escovação em ambiente escolar e avaliavam o efeito da ação posteriormente. Eles relataram uma queda considerável do índice de placa dos pré-escolares após essa intervenção. Pivotto A, et al. (2013) enfatizaram que a escola deve ser uma das principais instituições onde 
se fomenta a saúde, através de programas de educação em saúde bucal voltados para a ampliação da informação da família e dos professores.

A escovação diária através da utilização de escovas dentárias com dentifrícios fluoretados é um método eficaz no controle do biofilme. Esse método é um dos mais utilizados e serve como principal forma de controle do biofilme e consequentemente da cárie e da doença periodontal, porque agem desorganizando a placa bacteriana impedindo sua proliferação (RODRIGUES AP, et al., 2016; FILOGÔNIO CFB, et al., 2011; ZANATTA FB, et al., 2012).

Outros aditivos aos dentifrícios além do flúor são constantemente testados para saber se influenciam ou não no controle do biofilme. Filogônio CFB, et al. (2011) avaliaram se a adição de um óleo vegetal e de um óleo mineral a um dentifrício comercializado teria influência no controle de cárie e biofilme entre jovens de 18-21 anos e conclui positivamente sobre a ação deles.

Quanto à limpeza interproximal dentária, o fio dental realiza um papel de suma importância, porém seu uso ainda não ocorre corretamente, nem com a frequência necessária. Pivotto A, et al. (2013) avaliaram os hábitos de higiene oral de 202 escolares e observaram que o fio dental não era utilizado por $68 \%$ (137) dos mesmos.

O fato é que ainda há pouco conhecimento dos pacientes sobre a importância e a forma correta de higienização interdental, exigindo por parte dos cirurgiões-dentistas reeducarem seus pacientes para motiva-los ao uso do fio (VELÁZQUEZ FA, et al., 2017; PIVOTTO A, et al., 2013). Velázquez FA, et al. (2017) realizaram um estudo para saber se o uso do fio dental em anel entre jovens estudantes de odontologia auxiliaria no controle do biofilme dental e gengivite e concluiu que esse método foi estatisticamente melhor para controle de placa que o método tradicional.

A correlação da dieta/alimentação dos pacientes com a atividade cariogênica e problemas periodontais apresentados também é fator bem discutido na odontologia. Mahajan N, et al. (2014) relataram a influência dos alimentos no surgimento da cárie realizando uma comparação de pacientes que consumiam sucos de frutas com sacarose natural ou com açúcar adicionado e concluíram que todos provocam queda no ph tornando-o mais cariogênico.

Os profissionais da odontologia devem ter o cuidado de incluir em suas consultas parte dedicada à orientação do paciente e/ou de seus responsáveis, explicando como a doença cárie e periodontal se desenvolvem e como podem ser prevenidas. Entende-se que é função do cirurgião dentista a individualização dessa orientação. A orientação sobre o controle químico/mecânico do biofilme deve ser baseada na avaliação de cada caso clínico, propondo a associação de métodos, quando necessário.

\section{CONSIDERAÇÕES FINAIS}

O controle do biofilme é importante na prevenção das doenças cárie e dos problemas periodontais, que estão entre os principais problemas orais. É importante a conscientização do paciente e do cirurgiãodentista de que os tratamentos preventivos são imprescindíveis para preservação da saúde bucal. Os métodos químicos e mecânicos de higiene oral mostram-se como a melhor maneira de evitar patologias bucais causadas pelo biofilme bacteriano. Tais métodos devem ser empregados de diferentes formas, de acordo com o perfil de cada paciente.

\section{REFERÊNCIAS}

1. ADAM R, et al. Randomized controlled trial assessing plaque removal of an oscillating-rotating electric toothbrush with micro-vibrations. International Dental Journal. 2020; 70(1) 22-27.

2. ANSARI G, et al. Comparing the effect of dry and wet brushing on dental plaque removal in children. Journal of Indian Society of Pedodontics and Preventive Dentistry. 2020; 37(1) 292-296.

3. COSTA A, et al. Avaliação do índice de biofilme dentário, do deterioro e dos cuidados relativos ao armazenamento e desinfecção das escovas dentais de crianças de uma creche do sul de Minas Gerais. Braz J Periodontol. 2014; 24(2) 7-12.

4. FERREIRA R, et al. Prevenção e tratamento periodontal em pacientes com síndrome de Down: uma revisão sistemática. Plos One, 2016; 11(6) 1-16. 
5. FIGUERO E, et al. Efficacy of adjunctive therapies in patients with gingival inflammation. A systematic review and meta-analysis. J. Clin. Periodontol., 2019.

6. FILOGÔNIO CFB, et al. Effect of vegetable oil (Brazil not oil) and mineral oil (liquid petrolatum) on dental biofilm control. Braz Oral Res., 2011; 25(6) 556-561.

7. GONÇALVES EM, et al. Grau de conhecimento dos cirurgiões-dentistas na prescrição de colutórios e dentifrícios. Rev. Periodontia., 2010; 20(4) 51-55.

8. HAAS AN, et al. Dental studiens overall knowledge regarding oral antiseptics. Periodontia, 2010; 3(3) 47-52.

9. JAYAKUMAR A, et al. Papel do dentifrício na remoção da placa: um ensaio clínico. Indian J. Dent. Res., 2010; 21(2) 213-217.

10. KUBO FMM, MIALHE FL. Fio dental: da dificuldade ao êxito na remoção do biofilme interproximal. Arq. Odontol., $2011 ; 47(1)$ 51-55.

11.LANG T, et al. Clinical validation of robot simulation of toothbrushing - comparative plaque removal efficacy. BMC Oral Health, 2014; 14-82.

12.MAHAJAN N, et al. Efeito do consumo comum de açúcar e bebidas de frutas isentas de açúcar na modulação do ião hidrogênio da placa dental humana. J. Indian Soc. Pedod. Prev. Dent., 2014; 32(1) 26-32.

13.MARTINS RS, et al. Composição, princípios ativos e indicações clínicas dos dentifrícios: uma revisão da literatura entre 1989 e 2011. J. Health Sci. Inst., 2012; 30(3) 287-291.

14.PEDRAZZI V, et al. Métodos mecânicos para o controle do biofilme dentário supragengival. Rev. Periodontia, 2009; 19(3) 26-33.

15.PITHON MM, et al. Effectiveness of different mechanical bacterial plaque removal methods in patients with fixed orthodontic appliance: a systematic review and meta-analysis. Biosci. J., 2017; 33(2) 537-554.

16.PIVOTTO A, et al. Hábitos de higiene bucal e índice de higiene oral de escolares do ensino público. Rev. Bras. Promoc. Saúde, 2013; 26(4) 455-461.

17.RIBEIRO AA, et al. The oral bacterial microbiome of occlusal surfaces in children and its association with diet and caries. Plos One, 2017; 12(7) 1-16.

18.RODE SM, et al. Controle diário do biofilme e saúde bucal: consenso sobre o desafio epidemiológico - Painel Consultivo Latino-Americano. Braz Oral Res., 2012; 26(1) 133-143.

19.RODRIGUES AP, et al. Escovagem de dentes em ambiente escolar e redução do índice de placa bacteriana: avaliação da efetividade de um projeto de saúde oral. Rev. Port. Saúde Pública, 2016; 34(3) 244-249.

20.VERDE ME, et al. Effect of biphosphonates on the levels of rankl and opg in gingival crevicular fluido f patients with periodontal disease and post-menopausal osteoporosis. Acta Odontol. Latinoam., 2015; 28(3) 215-221.

21.VERKAIK MJ, et al. Eficácia e mecanismos de não-antibacterianos, controle de placa química por dentífricos - um estudo in vitro. Clin. Oral Investig., 2010; 14(4) 403-409.

22.VELÁZQUEZ FA, et al. Effectiveness of flo ssing loops in the controlo of the gingival health. Clin. Exp. Dent., 2017; 9(6) 756-761.

23.ZANATTA FB, et al. Supragingival Plaque Removal with and without Dentifrice: A Randomized Controlled Clinical Trial. Braz. Dent. J., 2012; 23(3) 235-240. 